\title{
Sistem Pendukung Keputusan Untuk Rekrutmen Android Developer Pada CV. KHz Technology Menggunakan Metode Preference Selection Index
}

\author{
Saniman *, Guntur Syahputra *, Nurcahyo Budi Nugroho*, Imanuel Zega** \\ * Program Studi Sistem Komputer, STMIK Triguna Dharma \\ ** Program Studi Sistem Informasi, STMIK Triguna Dharma
}

\begin{abstract}
Abstrak
$\mathrm{CV}$. $\mathrm{KHz}$ Technology merupakan sebuah perusahaan yang mengelola jasa pembuatan website atau aplikasi mobile untuk kepentingan suatu perusahaan, instansi, atau lembagalembaga swasta lainnya. $\mathrm{CV}$. $\mathrm{KHz}$ selama ini mengalami permasalahan dalam perekrutan calon karyawan baru khususnya bidang android developer.

Dari permasalahan yang terjadi, dengan menggunakan Sistem Pendukung Keputusan akan dapat membantu dalam penyelesaian masalah yang terjadi dengan menggunakan metode Preference Selection Index yang akurat dan tepat sasaran dalam perekrutan karyawan android developer. Dalam menentukan bobot kriteria dengan metode Preference Selection Index hanya dengan memanfaatkan informasi yang diberikan dalam matriks keputusan, yaitu menggunakan pendekatan obyektif.

Hasil dari penelitian ini, sebuah aplikasi berbasis dekstop yang dapat mengimplementasikan metode Preference Selection Index untuk menghasilkan keputusan yang akurat dan tepat sesuai dengan kebutuhan $\mathrm{CV}$. $\mathrm{KHz}$ Technology.
\end{abstract}

Kata kunci : Rekrutmen, Sistem Pendukung Keputusan, Preference Selection Index.

\section{Abstract}

$\mathrm{CV}$. $\mathrm{KHz}$ Technology is a company that manages website or mobile application creation services for the benefit of a company, agency or other private institution. $\mathrm{CV}$. $\mathrm{KHz}$ has been experiencing problems in recruiting new employee candidates, especially in the field of android developers.

From the problems that occur, using a Decision Support System will be able to assist in solving problems that occur by using the Preference Selection Index method which is accurate and right on target in the recruitment of android developer employees. In determining the weight of the criteria using the Preference Selection Index method only by utilizing the information provided in the decision matrix, namely using an objective approach.

The results of this study, a desktop-based application that can implement the Preference Selection Index method to produce accurate and precise decisions according to the needs of CV. KHz Technology.

Keywords: Recruitment, Decision Support Systems, Preference Selection Index.

\section{PENDAHULUAN}

Di era modern saat ini, banyak perusahaan dalam bidang jasa maupun dagang untuk menjalankan kegiatan usahanya pada dasarnya juga memiliki tujuan untuk mendapatkan keuntungan yang diperoleh akan semakin meningkat. Hal terpenting dalam menentukan pencapaian keberhasilan selain penjualan adalah proses rekrutmen karyawan. Karyawan yang baik dan memenuhi standar kualifikasi hanya akan dapat diperoleh melalui upaya rekrutmen yang baik juga. Rekrutmen calon karyawan merupakan suatu cara dalam perusahaan untuk mendapatkan sumber daya manusia yang benar-benar tepat untuk menduduki suatu posisi tertentu yang ditawarkan oleh perusahaan [1] 
Pada era revolusi industri 4.0 membuat banyak teknologi baru yang memerlukan pengembangan seperti android developer. Android developer atau pengembangan android merupakan seseorang yang memiliki kemampuan dalam membangun sistem, merencanakan arsiktekturnya, mengimplementasi hingga mengembangkan sistem yang sudah dibuat tersebut untuk masa yang akan datang. Dari kebutuhan di atas dibutuhkan suatu cara yang tepat dalam perekrutan karyawan diantaranya menggunakan Sistem Pendukung Keputusan.

Sistem Pendukung Keputusan adalah sistem penghasil informasi yang ditujukan pada suatu masalah tertentu yang harus dipecahkan oleh manager dan dapat membantu manager dalam pengambilan keputusan [2]. Dalam sistem pendukung keputusan terdapat teknik untuk menyelesaikan masalah salah satunya yaitu metode Preference Selection Index (PSI).

Pada penelitian [3] meneliti tentang pemanfaatan metode Preference Selection Index (PSI) untuk menentukan bobot kriteria hanya dengan menggunakan informasi yang diberikan dalam matriks keputusan, yaitu menggunakan pendekatan obyektif untuk menentukan bobot kriteria.

Dari latar belakang diatas maka disusunlah penelitian ini dengan judul "Sistem Pendukung Keputusan Untuk Rekrutmen Android Developer Pada CV. KHz Technology Menggunakan Metode Preference Selection Index".

\section{METODE PENELITIAN}

\subsection{Metode Penelitian}

Metode penelitian umumnya menggunakan konsep metodologi penelitian jenis Research and Development. Penelitian merupakan pencarian terencana atau penyelidikan kritis yang bertujuan untuk menemukan pengetahuan atau harapan baru bahwa pengetahuan semacam itu akan bermanfaat dalam mengembangkan suatu produk atau layanan baru. Berikut merupakan data yang telah diperoleh dari hasil penelitian adalah sebagai berikut:

1. Data Kriteria

Tabel 3.1 Kriteria keterangan

\begin{tabular}{|c|c|l|c|}
\hline No & $\begin{array}{c}\text { Kode } \\
\text { Kriteria }\end{array}$ & \multicolumn{1}{|c|}{ Keterangan } & Jenis \\
\hline 1 & C1 & Pendidikan & Benefit \\
\hline 2 & C2 & Pengalaman & Benefit \\
\hline 3 & C3 & Kemampuan Graphical User Interface & Benefit \\
\hline 4 & C4 & Kemampuan DBMS (JSON, Firebase, MysQL, SQLite) & Benefit \\
\hline 5 & C5 & Kemampuan Integrasi API & Benefit \\
\hline
\end{tabular}

Tabel 3.1 Kriteria keterangan (Lanjutan)

\begin{tabular}{|c|c|l|c|}
\hline 6 & C6 & $\begin{array}{l}\text { Kemampuan Penguasaan Editor Android (Eclipse, } \\
\text { Android Studio dll) }\end{array}$ & Benefit \\
\hline 7 & C7 & Pernah Uploading ke Playstore & Benefit \\
\hline 8 & C8 & Kemampuan Framework PHP & Benefit \\
\hline
\end{tabular}

Berikut ini merupakan tabel dari setiap kriteria yang akan digunakan dalam pengolahan data dengan metode Preference Selection Index yaitu:

a. Tabel Kriteria Pendidikan

Tabel 3.2 Kriteria Pendidikan

\begin{tabular}{|c|l|c|}
\hline NO & \multicolumn{1}{|c|}{ Jenjang Pendidikan } & Bobot Kriteria \\
\hline 1 & Strata 2 & 5 \\
\hline 2 & Strata 1 & 4 \\
\hline 3 & Diploma 3 & 3 \\
\hline 4 & Sekolah Menengah Kejuruan (RPL) & 2 \\
\hline
\end{tabular}


b. Tabel Kriteria Pengalaman

Tabel 3.3 Kriteria Pengalaman

\begin{tabular}{|c|l|c|}
\hline NO & \multicolumn{1}{|c|}{ Pengalaman } & Bobot Kriteria \\
\hline 1 & $0-1$ Tahun & 1 \\
\hline 2 & $>1$ Tahun s/d 2 Tahun & 2 \\
\hline 3 & $>2$ Tahun s/d 3 Tahun & 3 \\
\hline 4 & $>3$ Tahun s/d 4 Tahun & 4 \\
\hline 5 & $>4$ Tahun & 5 \\
\hline
\end{tabular}

c. Tabel Kemampuan Graphical User Interface

Tabel 3.4 Kriteria Kemampuan Graphical User Interface

\begin{tabular}{|c|l|c|}
\hline NO & Kemampuan Graphical User Interface & Bobot Kriteria \\
\hline 1 & Sangat Baik & 5 \\
\hline 2 & Baik & 4 \\
\hline 3 & Cukup & 3 \\
\hline 4 & Kurang & 2 \\
\hline 5 & Sangat Kurang & 1 \\
\hline
\end{tabular}

d. Tabel Kemampuan DBMS (JSON, Firebase, MysQL, SQLite)

Tabel 3.5 Kemampuan DBMS

\begin{tabular}{|c|l|c|}
\hline NO & \multicolumn{1}{|c|}{ Kemampuan DBMS } & Bobot Kriteria \\
\hline 1 & Sangat Baik & 5 \\
\hline 2 & Baik & 4 \\
\hline 3 & Cukup & 3 \\
\hline 4 & Kurang & 2 \\
\hline 5 & Sangat Kurang & 1 \\
\hline
\end{tabular}

e. Tabel Kemampuan Integrasi API

Tabel 3.6 Kemampuan Integrasi API

\begin{tabular}{|c|l|c|}
\hline NO & \multicolumn{1}{|c|}{ Kemampuan Integrasi API } & Bobot Kriteria \\
\hline 1 & Sangat Baik & 5 \\
\hline 2 & Baik & 4 \\
\hline 3 & Cukup & 3 \\
\hline 4 & Kurang & 2 \\
\hline 5 & Sangat Kurang & 1 \\
\hline
\end{tabular}

f. Tabel Kemampuan Penguasaan Editor Android (Eclipse, Android Studio)

Tabel 3.7 Kemampuan Penguasaan Editor Android

\begin{tabular}{|c|l|c|}
\hline NO & Kemampuan Penguasaan Editor Android & Bobot Kriteria \\
\hline 1 & Sangat Baik & 5 \\
\hline 2 & Baik & 4 \\
\hline
\end{tabular}




\begin{tabular}{|l|l|c|}
3 & Cukup & 3 \\
\hline 4 & Kurang & 2 \\
\hline 5 & Sangat Kurang & 1 \\
\hline
\end{tabular}

g. Tabel Pernah Uploading ke Playstore

Tabel 3.8 Pernah Uploading ke Playstore

\begin{tabular}{|c|l|c|}
\hline NO & \multicolumn{1}{|c|}{ Pernah Uploading ke Playstore } & Bobot Kriteria \\
\hline 1 & Pernah & 2 \\
\hline 2 & Tidak Pernah & 1 \\
\hline
\end{tabular}

h. Tabel Kemampuan Framework PHP

Tabel 3.9 Kemampuan Framework PHP

\begin{tabular}{|c|l|c|}
\hline NO & \multicolumn{1}{|c|}{ Kemampuan Framework PHP } & Bobot Kriteria \\
\hline 1 & Sangat Baik & 5 \\
\hline 2 & Baik & 4 \\
\hline 3 & Cukup & 3 \\
\hline 4 & Kurang & 2 \\
\hline 5 & Sangat Kurang & 1 \\
\hline
\end{tabular}

2. Data Alternatif

Tabel 3.10 Data Primer Dari Perusahaan

\begin{tabular}{|c|c|c|c|c|c|c|c|c|c|}
\hline \multirow{2}{*}{ No } & \multirow{2}{*}{$\begin{array}{l}\text { Nama } \\
\text { Pelamar }\end{array}$} & \multicolumn{8}{|c|}{ Nama Kriteria } \\
\hline & & C1 & $\mathrm{C} 2$ & $\mathrm{C} 3$ & C4 & C5 & C6 & C7 & C8 \\
\hline 1 & Hasan Ryadi & $\begin{array}{c}\text { Strata } \\
1\end{array}$ & $\begin{array}{c}1,3 \\
\text { Bulan }\end{array}$ & Baik & $\begin{array}{c}\text { Sangat } \\
\text { Baik }\end{array}$ & Baik & Baik & Pernah & Baik \\
\hline 2 & $\begin{array}{l}\text { Yongki } \\
\text { Purwanto }\end{array}$ & $\begin{array}{c}\text { Strata } \\
1\end{array}$ & $\begin{array}{c}3,5 \\
\text { Bulan }\end{array}$ & $\begin{array}{c}\text { Sangat } \\
\text { Baik }\end{array}$ & Cukup & Baik & $\begin{array}{c}\text { Sangat } \\
\text { Baik }\end{array}$ & Pernah & $\begin{array}{c}\text { Sang } \\
\text { at } \\
\text { Baik }\end{array}$ \\
\hline 3 & $\begin{array}{l}\text { Deni Agus } \\
\text { Simarmata }\end{array}$ & SMK & $\begin{array}{c}1,8 \\
\text { Bulan }\end{array}$ & Cukup & Baik & Baik & Cukup & $\begin{array}{l}\text { Tidak } \\
\text { Pernah }\end{array}$ & $\begin{array}{c}\text { Kura } \\
\text { ng }\end{array}$ \\
\hline 4 & $\begin{array}{l}\text { Andi } \\
\text { Lukman }\end{array}$ & D III & $\begin{array}{c}4,6 \\
\text { Bulan }\end{array}$ & $\begin{array}{c}\text { Sangat } \\
\text { Baik }\end{array}$ & Baik & Cukup & $\begin{array}{c}\text { Sangat } \\
\text { Baik }\end{array}$ & Pernah & $\begin{array}{c}\text { Sang } \\
\text { at } \\
\text { Baik }\end{array}$ \\
\hline 5 & $\begin{array}{l}\text { Anita } \\
\text { Widiyastuti }\end{array}$ & SMK & $\begin{array}{c}6 \\
\text { Bulan }\end{array}$ & Baik & $\begin{array}{l}\text { Sangat } \\
\text { Kurang }\end{array}$ & Baik & Kurang & $\begin{array}{l}\text { Tidak } \\
\text { Pernah }\end{array}$ & $\begin{array}{c}\text { Kura } \\
\text { ng }\end{array}$ \\
\hline 6 & $\begin{array}{l}\text { Stephan } \\
\text { Nugroho }\end{array}$ & $\begin{array}{c}\text { Strata } \\
2\end{array}$ & $\begin{array}{c}3 \\
\text { Tahun }\end{array}$ & $\begin{array}{c}\text { Sangat } \\
\text { Baik }\end{array}$ & Baik & $\begin{array}{c}\text { Sangat } \\
\text { Baik }\end{array}$ & Cukup & $\begin{array}{l}\text { Tidak } \\
\text { Pernah }\end{array}$ & Baik \\
\hline 7 & $\begin{array}{l}\text { Syarifah } \\
\text { Aini }\end{array}$ & D III & $\begin{array}{c}1 \\
\text { Tahun }\end{array}$ & Cukup & Baik & Baik & $\begin{array}{c}\text { Sangat } \\
\text { Baik }\end{array}$ & Pernah & $\begin{array}{c}\text { Sang } \\
\text { at } \\
\text { Kura } \\
\text { ng }\end{array}$ \\
\hline 8 & $\begin{array}{l}\text { Vera Mariati } \\
\text { Magdalena } \\
\text { Purba }\end{array}$ & SMK & $\begin{array}{c}3 \\
\text { Bulan }\end{array}$ & Kurang & Cukup & Baik & Kurang & $\begin{array}{l}\text { Tidak } \\
\text { Pernah }\end{array}$ & Baik \\
\hline
\end{tabular}




\begin{tabular}{|c|l|c|c|c|c|c|c|c|c|}
\hline 9 & $\begin{array}{l}\text { Diarmansyah } \\
\text { Batubara }\end{array}$ & SMA & $\begin{array}{c}\text { Tidak } \\
\text { Ada }\end{array}$ & $\begin{array}{c}\text { Sangat } \\
\text { Kurang }\end{array}$ & Kurang & Baik & Baik & $\begin{array}{c}\text { Tidak } \\
\text { Pernah }\end{array}$ & Baik \\
\hline
\end{tabular}

Tabel 3.10 Data Primer Dari Perusahaan (Lanjutan)

\begin{tabular}{|c|l|c|c|c|c|c|c|c|c|}
\hline 10 & $\begin{array}{l}\text { Herlina } \\
\text { Pardede }\end{array}$ & D III & $\begin{array}{c}2 \\
\text { Tahun }\end{array}$ & Baik & Cukup & Kurang & Baik & Pernah & Baik \\
\hline
\end{tabular}

Tabel 3.10 Data Primer Dari Perusahaan (Lanjutan)

\begin{tabular}{|c|l|c|c|c|c|c|c|c|c|}
\hline 10 & $\begin{array}{l}\text { Herlina } \\
\text { Pardede }\end{array}$ & D III & $\begin{array}{c}2 \\
\text { Tahun }\end{array}$ & Baik & Cukup & Kurang & Baik & Pernah & Baik \\
\hline
\end{tabular}

\subsection{Flowchart Algoritma Preference Selection Index}

Berikut ini merupakan flowchart dari algoritma preference selection index yaitu sebagai berikut:

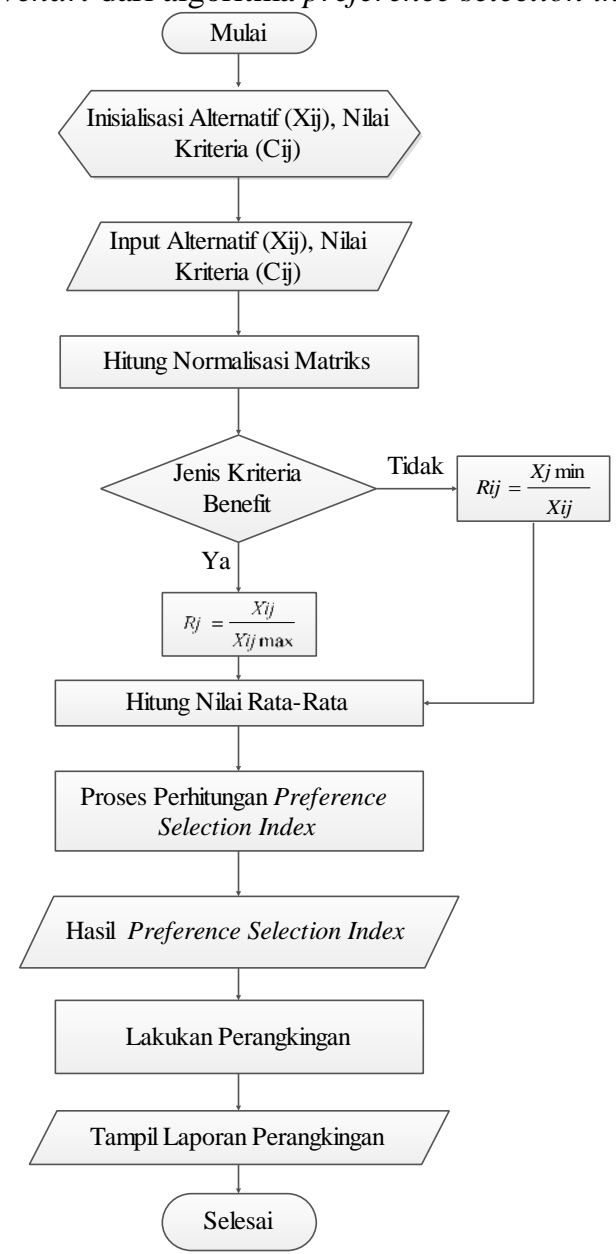

Gambar 3.1 Flowchart Algoritma Preference Selection Index

2.3 Algoritma Preference Selection Index

Tabel 3.11 Hasil Konversi Data Alternatif

\begin{tabular}{|c|l|c|c|c|c|c|c|c|c|}
\hline No & \multicolumn{1}{|c|}{ Nama Pelamar } & C1 & C2 & C3 & C4 & C5 & C6 & C7 & C8 \\
\hline 1 & Hasan Ryadi & 4 & 2 & 4 & 5 & 4 & 4 & 2 & 4 \\
\hline 2 & Yongki Purwanto & 4 & 4 & 5 & 3 & 4 & 5 & 2 & 5 \\
\hline
\end{tabular}




\begin{tabular}{l|l|l|l|l|l|l|l|l|l}
3 & Deni Agus Simarmata & 2 & 2 & 3 & 4 & 4 & 3 & 1 & 2 \\
\hline
\end{tabular}

Tabel 3.11 Hasil Konversi Data Alternatif (Lanjutan)

\begin{tabular}{|l|l|l|l|l|l|l|l|l|l|}
\hline 4 & Andi Lukman & 3 & 5 & 5 & 4 & 3 & 5 & 2 & 5 \\
\hline 5 & Anita Widiyastuti & 2 & 1 & 4 & 1 & 4 & 2 & 1 & 2 \\
\hline 6 & Stephan Nugroho & 5 & 3 & 5 & 4 & 5 & 3 & 1 & 4 \\
\hline 7 & Syarifah Aini & 3 & 1 & 3 & 4 & 4 & 5 & 2 & 1 \\
\hline 8 & Vera Mariati Magdalena Purba & 2 & 1 & 2 & 3 & 4 & 2 & 1 & 4 \\
\hline 9 & Diarmansyah Batubara & 1 & 1 & 1 & 2 & 4 & 4 & 1 & 4 \\
\hline 10 & Herlina Pardede & 3 & 2 & 4 & 3 & 2 & 4 & 2 & 4 \\
\hline
\end{tabular}

Berikut ini adalah matriks keputusan berdasarkan data hasil konversi nilai alternatif yaitu sebagai berikut:

Matriks $X_{i j}=\left[\begin{array}{cccccccc}4 & 2 & 4 & 5 & 4 & 4 & 2 & 4 \\ 4 & 4 & 5 & 3 & 4 & 5 & 2 & 5 \\ 2 & 2 & 3 & 4 & 4 & 3 & 1 & 2 \\ 3 & 5 & 5 & 4 & 3 & 5 & 2 & 5 \\ 2 & 1 & 4 & 1 & 4 & 2 & 1 & 2 \\ 5 & 3 & 5 & 4 & 5 & 3 & 1 & 4 \\ 3 & 1 & 3 & 4 & 4 & 5 & 2 & 1 \\ 2 & 1 & 2 & 3 & 4 & 2 & 1 & 4 \\ 1 & 1 & 1 & 2 & 4 & 4 & 1 & 4 \\ 3 & 2 & 4 & 3 & 2 & 4 & 2 & 4\end{array}\right]$

1. Mencari Maximum dan Minimum Dari Setiap Alternatif

Tabel 3.11 Nilai Maximum dan Minimum

\begin{tabular}{|l|c|c|c|c|c|c|c|c|}
\hline \multicolumn{1}{|c|}{ Nilai Maximum dan Nilai Minimum Alternatif } \\
\hline Nilai Maximum & 5 & 5 & 5 & 5 & 5 & 5 & 2 & 5 \\
\hline Nilai Minimum & 1 & 1 & 1 & 1 & 2 & 2 & 1 & 1 \\
\hline
\end{tabular}

2. Melakukan Normalisasi Matriks Keputusan

Berikut ini adalah normalisasi matriks dari nilai alternatif sesuai dengan jenis.

Kriteria keuntungan (benefit)

$R_{i j}=\frac{X_{i j}}{X_{i j} \max }$

Kriteria biaya (cost)

$R_{i j}=\frac{X_{i j} \min }{X_{i j}}$

Berikut ini adalah hasil normalisasi matriks keputusan secara keseluruhan yaitu sebagai berikut:

$$
\text { Matriks } R_{i j}=\left[\begin{array}{cccccccc}
0,8 & 0,4 & 0,8 & 1 & 0,8 & 0,8 & 1 & 0,8 \\
0,8 & 0,8 & 1 & 0,6 & 0,8 & 1 & 1 & 1 \\
0,4 & 0,4 & 0,6 & 0,8 & 0,8 & 0,6 & 0,5 & 0,4 \\
0,6 & 1 & 1 & 0,8 & 0,6 & 1 & 1 & 1 \\
0,4 & 0,2 & 0,8 & 0,2 & 0,8 & 0,4 & 0,5 & 0,4 \\
1 & 0,6 & 1 & 0,8 & 1 & 0,6 & 0,5 & 0,8 \\
0,6 & 0,2 & 0,6 & 0,8 & 0,8 & 1 & 1 & 0,2 \\
0,4 & 0,2 & 0,4 & 0,6 & 0,8 & 0,4 & 0,5 & 0,8 \\
0,2 & 0,2 & 0,2 & 0,4 & 0,8 & 0,8 & 0,5 & 0,8 \\
0,6 & 0,4 & 0,8 & 0,6 & 0,4 & 0,8 & 1 & 0,8
\end{array}\right]
$$

3. Menghitung Nilai Rata-Rata Matriks

Melakukan penjumlahan dari nilai rata-rata matriks dari setiap atribut sebagai berikut:

$N_{j}=\frac{1}{N} \sum_{i=1}^{m} R i j$

Hasil perhitungan yang diperoleh dari perhitungan di atas adalah sebagai berikut: 
$\sum_{i=1}^{n} R_{i j}=\left[\begin{array}{llllllll}5,8 & 4,4 & 7,2 & 6,6 & 7,6 & 7,4 & 7,5 & 7\end{array}\right]$

Menghitung nilai mean dari hasil yang telah diperoleh di atas, yaitu:

$\sum_{i=1}^{n} R_{i j}=\frac{1}{10} \times 5,8=0,58$

$\sum_{i=1}^{n} R_{i j}=\frac{1}{10} \times 4,4=0,44$

$\sum_{i=1}^{n} R_{i j}=\frac{1}{10} \times 7,2=0,72$

$\sum_{i=1}^{n} R_{i j}=\frac{1}{10} \times 6,6=0,66$

$\sum_{i=1}^{n} R_{i j}=\frac{1}{10} \times 7,6=0,76$

$\sum_{i=1}^{n} R_{i j}=\frac{1}{10} \times 7,4=0,74$

$\sum_{i=1}^{n} R_{i j}=\frac{1}{10} \times 7,5=0,75$

$\sum_{i=1}^{n} R_{i j}=\frac{1}{10} \times 7=0,7$

4. Menghitung Nilai Variasi Preferensi.

Menentukan nilai variasi preferensi dalam kaitannya dengan setiap kriteria menggunakan rumuss sebagai berikut:

$\emptyset_{j}=\sum_{i=1}^{m}\left[R_{i j}-N_{j}\right]^{2}$

Berikut ini merupakan hasil perhitungan pangkat pada matriks nilai variasi preferensi $\left(\varnothing_{j}\right)$

$\emptyset_{j}=\left[\begin{array}{llllllll}0,048 & 0,002 & 0,006 & 0,116 & 0,002 & 0,004 & 0,063 & 0,010 \\ 0,048 & 0,130 & 0,078 & 0,004 & 0,002 & 0,068 & 0,063 & 0,090 \\ 0,032 & 0,002 & 0,014 & 0,020 & 0,002 & 0,020 & 0,063 & 0,090 \\ 0,000 & 0,314 & 0,078 & 0,020 & 0,026 & 0,068 & 0,063 & 0,090 \\ 0,032 & 0,058 & 0,006 & 0,212 & 0,002 & 0,116 & 0,063 & 0,090 \\ 0,176 & 0,026 & 0,078 & 0,020 & 0,058 & 0,020 & 0,063 & 0.010 \\ 0,000 & 0,058 & 0,014 & 0,020 & 0,002 & 0,068 & 0,063 & 0,250 \\ 0,032 & 0,058 & 0,102 & 0,004 & 0,002 & 0,116 & 0,063 & 0,010 \\ 0,144 & 0,058 & 0,270 & 0,068 & 0,002 & 0,004 & 0,063 & 0,010 \\ 0,000 & 0,002 & 0,006 & 0,004 & 0,130 & 0,004 & 0,063 & 0,010\end{array}\right]$

Kemudian menjumlahkan hasil nilai pangkat pada matriks variasi preferensi $\left(\emptyset_{j}\right)$

Hasil penjumlahan matriks variasi preferensi adalah sebagai berikut:

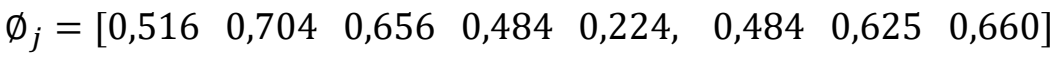

5. Menentukan Nilai Dalam Preferensi

$\Omega_{j}=1-\emptyset_{j}$

$\Omega_{j}=1-0,516=0,484$

$\Omega_{j}=1-0,704=0,296$

$\Omega_{j}=1-0,656=0,344$

$\Omega_{j}=1-0,484=0,516$

$\Omega_{j}=1-0,224=0,776$

$\Omega_{j}=1-0,484=0,516$

$\Omega_{j}=1-0,625=0,375$

$\Omega_{j}=1-0,660=0,340$

Berikut merupakan hasil dari pengurangan nilai dalam preferensi yang terdiri dari yaitu:

$\Omega_{j}=\left[\begin{array}{llllllll}0,484 & 0,296 & 0,344 & 0,516 & 0,776 & 0,516 & 0,375 & 0,340\end{array}\right]$

Menghitung total nilai:

$\sum \Omega_{j}=0,484+0,296+0,344+0,516+0,776+0,516+0,375+0,340=3,647$ 
6. Menentukan Kriteria Bobot

Adapun rumus yang akan digunakan dalam menghitung kriteria bobot adalah sebagai berikut:

$W_{j}=\frac{\Omega_{j}}{\sum_{j=1}^{n} \Omega_{j}}$

$W_{j}=\frac{\Omega_{j}}{\sum_{j=1}^{n} \Omega_{j}}=\frac{0,484}{3,647}=0,133$

$W_{j}=\frac{\Omega_{j}}{\sum_{j=1}^{n} \Omega_{j}}=\frac{0,296}{3,647}=0,081$

$W_{j}=\frac{\Omega_{j}}{\sum_{j=1}^{n} \Omega_{j}}=\frac{0,344}{3,647}=0,094$

$W_{j}=\frac{\Omega_{j}}{\sum_{j=1}^{n} \Omega_{j}}=\frac{0,516}{3,647}=0,141$

$W_{j}=\frac{\Omega_{j}}{\sum_{j=1}^{n} \Omega_{j}}=\frac{0,776}{3,647}=0,231$

$W_{j}=\frac{\Omega_{j}}{\sum_{j=1}^{n} \Omega_{j}}=\frac{0,516}{3,647}=0,141$

$W_{j}=\frac{\Omega_{j}}{\sum_{j=1}^{n} \Omega_{j}}=\frac{0,375}{3,647}=0,103$

$W_{j}=\frac{\Omega_{j}}{\sum_{j=1}^{n} \Omega_{j}}=\frac{0,340}{3,647}=0,093$

Hasil perhitungan nilai keseluruhan kriteria bobot $W_{j}$ adalah sebagai berikut:

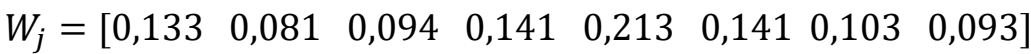

7. Menghitung Preference Selection Index

Untuk mendapatkan nilai preferensi indeks terbesar adalah dengan menggunakan rumus sebagai berikut:

$\emptyset_{i}=\sum_{j=1}^{n}\left(R_{i j} W_{j}\right)$

Hasil perhitungan perkalian pada matriks $\emptyset_{i}$ adalah sebagai berikut:

$\emptyset_{i}=\left[\begin{array}{llllllll}0,106 & 0,032 & 0,075 & 0,141 & 0,170 & 0,113 & 0,103 & 0,075 \\ 0,106 & 0,065 & 0,094 & 0,085 & 0,170 & 0,141 & 0,103 & 0,093 \\ 0,053 & 0,032 & 0,057 & 0,113 & 0,170 & 0,085 & 0,051 & 0,037 \\ 0,080 & 0,081 & 0,094 & 0,113 & 0,128 & 0,141 & 0,103 & 0,093 \\ 0,053 & 0,016 & 0,075 & 0,028 & 0,170 & 0,057 & 0,051 & 0,037 \\ 0,133 & 0,049 & 0,094 & 0,113 & 0,213 & 0,085 & 0,051 & 0,075 \\ 0,080 & 0,016 & 0,057 & 0,113 & 0,170 & 0,141 & 0,103 & 0,019 \\ 0,053 & 0,016 & 0,038 & 0,085 & 0,170 & 0,057 & 0,051 & 0,075 \\ 0,027 & 0,016 & 0,019 & 0,057 & 0,170 & 0,113 & 0,051 & 0,075 \\ 0,080 & 0,032 & 0,075 & 0,085 & 0,085 & 0,113 & 0,103 & 0,075\end{array}\right]$

Langkah terkahir adalah mencari nilai perangkingan yaitu sebagai berikut:

$\emptyset_{1}=0,106+0,032+0,075+0,141+0,170+0,113+0,103+0,075=0,816$

$\emptyset_{2}=0,106+0,065+0,094+0,085+0,170+0,141+0,103+0,093=0,858$

$\emptyset_{3}=0,053+0,032+0,057+0,113+0,170+0,085+0,051+0,037=0,599$

$\emptyset_{4}=0,080+0,081+0,094+0,113+0,128+0,141+0,103+0,093=0,834$

$\emptyset_{5}=0,053+0,016+0,075+0,028+0,170+0,057+0,051+0,037=0,489$

$\emptyset_{6}=0,133+0,049+0,094+0,113+0,213+0,085+0,051+0,075=0,813$

$\emptyset_{7}=0,080+0,016+0,057+0,113+0,170+0,141+0,103+0,019=0,699$

$\emptyset_{8}=0,053+0,016+0,038+0,085+0,170+0,057+0,051+0,075=0,545$

$\emptyset_{9}=0,027+0,016+0,019+0,057+0,170+0,113+0,051+0,075=0,528$

$\emptyset_{10}=0,080+0,032+0,075+0,085+0,085+0,113+0,103+0,075=0,648$

8. Perangkingan 
Berdasarkan nilai $\emptyset_{i}$ di atas berikut ini adalah hasil dan perangkingan dari penilaian skala prioritas Project adalah sebagai berikut:

Tabel 3.12 Hasil Perangkingan Metode Preference Selection Index

\begin{tabular}{|c|l|c|c|}
\hline No & \multicolumn{1}{|c|}{ Nama Pelamar } & Nilai $\emptyset \mathbf{i}$ & Prioritas \\
\hline 1 & Hasan Ryadi & 0,816 & Prioritas 3 \\
\hline 2 & Yongki Purwanto & 0,858 & Prioritas 1 \\
\hline 3 & Deni Agus Simarmata & 0,599 & Prioritas 7 \\
\hline 4 & Andi Lukman & 0,834 & Prioritas 2 \\
\hline 5 & Anita Widiyastuti & 0,489 & Prioritas 10 \\
\hline 6 & Stephan Nugroho & 0,813 & Prioritas 4 \\
\hline 7 & Syarifah Aini & 0,699 & Prioritas 5 \\
\hline 8 & Vera Mariati Magdalena Purba & 0,545 & Prioritas 8 \\
\hline 9 & Diarmansyah Batubara & 0,528 & Prioritas 9 \\
\hline 10 & Herlina Pardede & 0,648 & Prioritas 6 \\
\hline
\end{tabular}

Dari hasil tabel perangkingan metode Preference Selection Index, maka hasil dapat diurutkan berdasarkan prioritas yaitu:

Tabel 3.13 Hasil Perangkingan Berdasarkan Prioritas

\begin{tabular}{|c|l|c|c|}
\hline No & \multicolumn{1}{|c|}{ Nama Pelamar } & Nilai $\emptyset \mathbf{i}$ & Prioritas \\
\hline 1 & Yongki Purwanto & 0,858 & Prioritas1 \\
\hline 2 & Andi Lukman & 0,834 & Prioritas 2 \\
\hline 3 & Hasan Ryadi & 0,816 & Prioritas 3 \\
\hline 4 & Stephan Nugroho & 0,813 & Prioritas 4 \\
\hline 5 & Syarifah Aini & 0,699 & Prioritas 5 \\
\hline 6 & Herlina Pardede & 0,648 & Prioritas 6 \\
\hline 7 & Deni Agus Simarmata & 0,599 & Prioritas 7 \\
\hline 8 & Vera Mariati Magdalena Purba & 0,545 & Prioritas 8 \\
\hline 9 & Diarmansyah Batubara & 0,528 & Prioritas 9 \\
\hline 10 & Anita Widiyastuti & 0,489 & Prioritas 10 \\
\hline
\end{tabular}

Sesuai dengan perhitungan yang dilakukan dari awal hingga akhir, serta didukung dengan penentuan kriteria yang telah ditentukan sebelumnya, maka perekrutan karyawan android developer di CV. KHz Technology terpilih Yongki Purwanto sebagai pilihan prioritas utama.

\section{ANALISA DAN HASIL}

Implementasi sistem merupakan kegiatan akhir dari proses penerapan sistem, dimana sistem ini akan dioperasikan secara menyeluruh. Sebelum sistem benar-benar bisa digunakan dengan baik, sistem harus melalui tahap pengujian terlebih dahulu untuk menjamin tidak ada kendala yang muncul pada saat sistem digunakan. Implementasi yang dilakukan terdapat beberapa tahap dan prosedur untuk menyelesaikan analisa yaitu apalikasi yang disetujui, melakukan penginstalan, pengujian data dan memulai menggunakan sistem baru. Implementasi sebagai dukungan sistem analisa diperlukan beberapa perangkat-perangkat sebagai berikut:

1. Tampilan Form Login 
Berikut ini merupakan tampilan dari form login yang berfungsi untuk melakukan proses validasi username dan password pengguna.

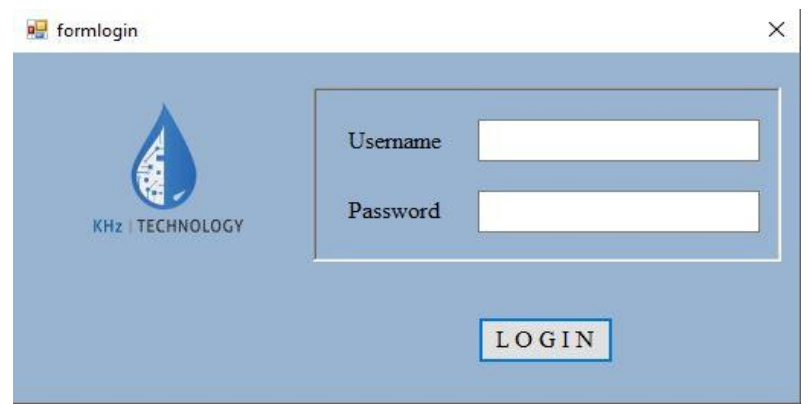

Gambar 3.1 Tampilan Login

2. Tampilan Menu Utama

Berikut ini adalah tampilan halaman menu utama:

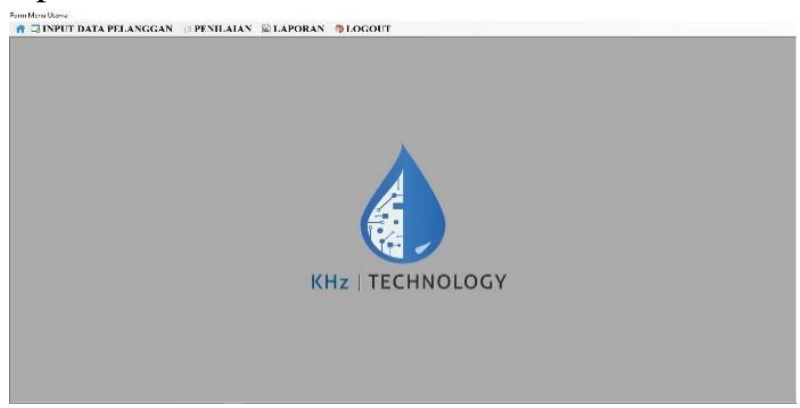

Gambar 3.2 Tampilan Menu Utama

3. Tampilan Halaman Input Data Alternatif

Berikut ini adalah tampilan halaman Data Alternatif adalah sebagai berikut:

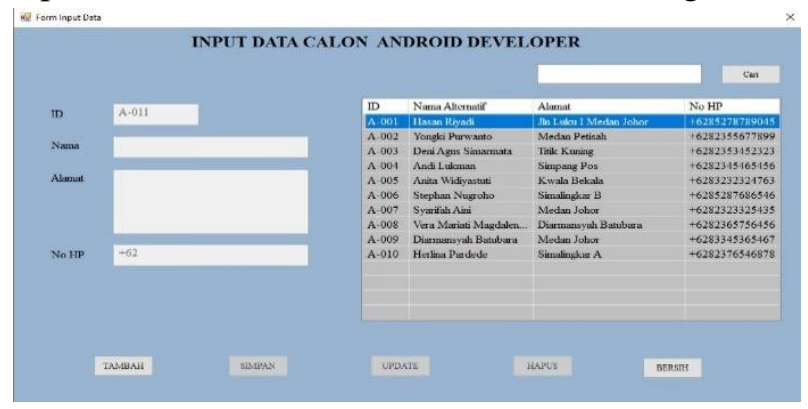

Gambar 3.3 Tampilan Form Input Alternatif

4. Tampilan Halaman Penilaian

Berikut ini adalah tampilan dari halaman penilaian akhir:

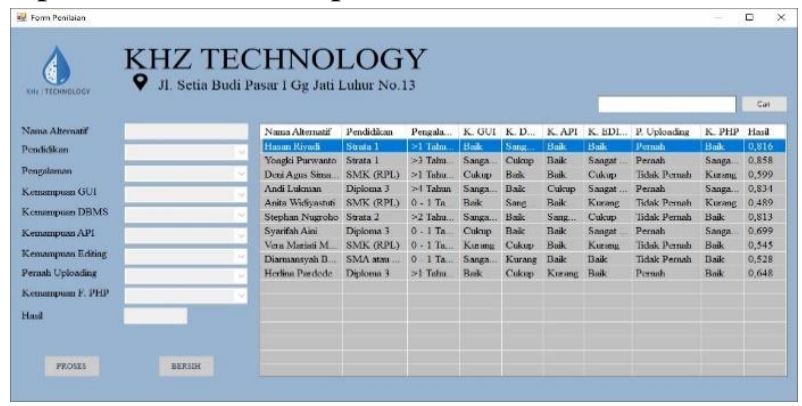

Gambar 3.4 Tampilan Halaman Penilaian 
5. Tampilan Halaman Laporan

Berikut ini adalah tampilan dari hasil perhitungan tersebut:

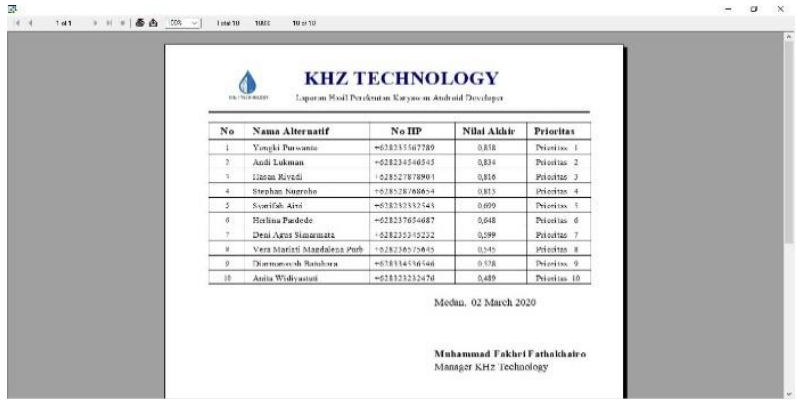

Gambar 3.5 Tampilan Laporan

\section{KESIMPULAN}

Jadi kesimpulan yang dapat disimpulkan dari hasil analisa perekrutan calon karyawan android developer adalah sebagai berikut:

1. Berdasarkan hasil analisa, metode Preference Selection Index dapat diterapkan dalam pemecahan masalah di $\mathrm{CV}$. $\mathrm{KHz}$ Technology terkait hal rekrutmen karyawan android developer.

2. Berdasarkan hasil penelitian, dalam merancang sistem pendukung keputusan berbasis dekstop yang mengadopsi metode Preference Selection Index dapat digunakan dalam penyelesaian masalah di CV. KHz Technology.

3. Aplikasi yang dibangun dengan menggunakan bahasa pemrograman Visual Studio dan database Microsoft Access dalam sistem pendukung keputusan dengan metode Preference Selection Index dapat dibangun.

\section{REFERENSI}

[1] M. S. Hartoko and S. E. Mm, "Rekrutmen Calon Karyawan Tetap ( Studi Kasus Politeknik LP3I Jakarta Kampus Pasar Minggu ),” vol. 4, no. 2, pp. 122-127, 2016.

[2] H. Susanto, "Penerapan Metode Additive Ratio Assessment ( Aras ) Dalam Pendukung Keputusan Pemilihan Susu Gym,” Maj. Ilm. INTI, vol. 13, pp. 1-5, 2018.

[3] Didie Nanda Pribadi, "Sistem Pendukung Keputusan Pemberian Reward kepada Karyawan Menggunakan Metode Perbadingan Eksponensial,” pp. 615-622, 2019. 